\title{
Understanding the value of clinical symptoms of
}

MSc. Pedro E. Fleitas ${ }^{1,2}$, PhD. Jorge A. Paz ${ }^{3}$, PhD. Mario I. Simoy ${ }^{4,5}$, MSc.

Carlos Vargas ${ }^{1}$, PhD. Rubén O. Cimino ${ }^{1,2}$, PhD. Alejandro J. Krolewiecki ${ }^{1^{\star}}$,

PhD. Juan P. Aparicio ${ }^{4,6}$.

1. Instituto de Investigaciones de Enfermedades Tropicales (IIET-CONICET), Universidad Nacional de Salta. San Ramón de la Nueva Orán, Salta, Argentina

2. Cátedra de Química Biología, Facultad de Ciencias Naturales, Universidad Nacional de Salta. Salta, Salta, Argentina

3. Instituto de Estudios Laborales y del Desarrollo Económico (IELDE), Consejo Nacional de Investigaciones Científicas y Técnicas (CONICET), Universidad Nacional de Salta. Salta, Salta, Argentina.

4. Instituto de Investigaciones en Energía no Convencional (INENCO), Consejo Nacional de Investigaciones Científicas y Técnicas (CONICET), Universidad Nacional de Salta, Salta, Argentina.

5. Instituto Multidisciplinario sobre Ecosistemas y Desarrollo Sustentable, Universidad Nacional del Centro de la Provincia de Buenos Aires. Tandil, Buenos Aires, Argentina.

6. Simon A. Levin Mathematical, Computational and Modeling Sciences Center, Arizona State University, Tempe, USA. 
medRxiv preprint doi: https://doi.org/10.1101/2020.10.07.20207019; this version posted October 16, 2020. The copyright holder for this preprint

(which was not certified by peer review) is the author/funder, who has granted medRxiv a license to display the preprint in perpetuity. It is made available under a CC-BY-NC-ND 4.0 International license.

22

${ }^{*}$ Corresponding author: PhD. Alejandro Krolewiecki.

23

Mail: alekrol@hotmail.com

24

Tel: +5491131838673

25

Work address: Instituto de Investigaciones de Enfermedades Tropicales

26

(IIET). Alvarado 751, San Ramon de la Nueva Oran, Salta, Argentina. Zip

27

Code: A4530.

28 


\section{Abstract}

\section{Background}

The new coronavirus SARS-CoV-2, the causative agent of COVID-19, is responsible for the current pandemic outbreak worldwide. However, there is limited information regarding the set of specific symptoms of COVID-19. Therefore, the objective of this study was to describe the main symptoms associated with COVID-19 to aid in the clinical diagnosis for the rapid identification of cases.

\section{Methods and findings}

A cross sectional study of all those diagnosed by RT-PCR for SARS-CoV-2 between April 1 and May 24 in Argentina was conducted. The data includes clinical and demographic information from all subjects at the time of presentation, which were uploaded to the centralized national reporting system at health centers. A total of 67318 individuals were included in this study, where $12 \%$ tested positive for SARS-CoV-2. The study population was divided in two age groups, a group aged 0 to 55 years-old ( $<56$ group), ( median $=32, n=48748)$ and another group aged 56 to 103 years-old ( $\geq 56$ group) (median $=72, n=18570$ ). Multivariate logistic regression analyses showed that out of a total of 23 symptoms, only five were found to have a positive association with COVID-19: anosmia (odds ratio [OR] 10.40, 95\% confidence interval [Cl] 8.20-13.10, <56 group; OR $6.09 \mathrm{Cl}$ 3.05-12.20, $\geq 56$ group) dysgeusia (OR 3.67, $\mathrm{Cl} 2.7-4.9,<56$ group; OR $3.53 \mathrm{Cl}$ 1.52-8.18, $\geq 56$ group), low grade fever (37.5-37.9응 $\mathrm{C}$ (OR 1.61, Cl 1.20-2.05, <56 
group; OR $1.80 \mathrm{Cl}$ 1.07-3.06, $\geq 56$ group), cough (OR 1.20, Cl 1.05-1.38, $<56$ group; OR $1.37 \mathrm{Cl} 1.04-1.80, \geq 56$ group) and headache only in <56 group (OR 1.71, Cl 1.48-1.99). In turn, at the time of presentation, the symptoms associated with respiratory problems: chest pain, tachypnea, dyspnea, respiratory failure and use of accessory muscles for breathing, had a negative association with COVID-19 (OR <1) or did not present statistical relevance $(\mathrm{OR}=1)$.

With the intention of helping the clinical diagnosis, we designed a model to be able to identify possible cases of COVID-19. This model included 16 symptoms, the age and sex of the individuals, and was able to detect $80 \%$ of those infected with SARS-CoV-2 with a specificity of $46 \%$.

\section{Conclusions}

64

65

66

67

68

69

The analysis of symptoms opens the opportunity for a guidance and improved symptoms based definition of suspected cases of COVID-19, where multiple factors (age, sex, symptoms and interaction between symptoms) are considered. We present a tool to help identify COVID-19 cases to provide quick information to aid decision-making by health personnel and program managers. 
71 The new coronavirus SARS-CoV-2, the causative agent of COVID-19, is

72 responsible for the current pandemic outbreak as declared by the World Health

73 Organization on January 30th 2020 (1). By September 2020, the number of people

74 infected with SARS-CoV-2 is over 28 million worldwide with more than 900

75 thousand deaths (2). The rapid spread of the virus has demonstrated its ability to overwhelm the health systems of developed countries and poses in danger countries with vulnerable health systems. These particular characteristics underline the adoption of social-distancing measures including quarantines, lockdowns and limitations in international travel implemented by most governments.

Until now, the most widely used diagnostic tool is real-time reverse transcriptase polymerase chain reaction (RT-PCR) from nasal and pharyngeal swabs (3). Although, RT-PCR is highly specific, has a suboptimal sensitivity (4), and false negatives have been reported (5). Without proven therapeutic drugs or vaccines, the identification and isolation of infected people through contact tracing or passive detection is of vital importance for controlling disease spread (4). In this context, an adequate characterization of suspected cases becomes of critical importance.

We analyzed the symptoms corresponding to a large database obtained from individuals evaluated by RT-PCR in Argentina in order to identify the symptoms associated with COVID-19 and develop a model to identify possible individuals infected with SARS-CoV-2. 


\section{$91 \quad$ Materials and Methods}

\section{Data source}

93 The data file was provided by the National Ministry of Health of Argentina

94 (Ministerio de Salud de la Nación Argentina. Dirección Nacional de Epidemiología

95 y Análisis de la Situación de Salud. Área de Vigilancia). The analysis included 67318 people evaluated through RT-PCR for SARS-CoV-2 throughout the country

97 from April 1 through May 24, 2020 and included in the registry of the National

98 Ministry of Health. Several variables including age, sex, RT-PCR result (positive or

99 negative), and symptoms at presentation were recorded in a structured 100 questionnaire for each individual. Symptoms (presence or absence) include 101 anosmia, dysgeusia, arthralgia, headache, confusion, seizures, diarrhea, dyspnea, 102 abdominal pain, chest pain, low grade fever (37.5-37.9ํㅡㄴ Celsius), high grade fever $103\left(\geq 38^{\circ} \mathrm{C}\right)$, respiratory failure, conjunctival injection, irritability, malaise, myalgia, food 104 refusal, tachypnea, use of accessory muscles for breathing (UAMB), cough and 105 vomiting. Before May 18 the form included 'odynophagia' and 'sore throat'. After 106 May 18 only odynophagia remained in the form. Therefore, all odynophagia 107 analyzes were performed considering the data from May 18 to May 24 (10225 108 individuals - $15 \%$ of the entire dataset), the period of time where only odynophagia 109 was available in the questionnaire. We did not impose any further exclusion criteria 110 to limit selection bias. This study is reported as per the Strengthening the Reporting 111 of Observational Studies in Epidemiology (STROBE) guidelines (S1 STROBE 112 Checklist, Supporting material). 


\section{Diagnosis by RT-PCR}

114 The diagnosis by RT-PCR was used as a reference standard for the design of the

115 regression model. All kits for use in Argentina were approved by the Administración

116 Nacional de Medicamentos, Alimentos y Tecnología Médica. A fluid sample was

117 taken with a swab from each nostril and pharynx. From these samples, an RNA

118 extraction was performed for the subsequent RT-PCR.

119 Data analysis.

120 Symptoms of COVID-19 have been reported to differ in different age groups (6),

121 therefore two age categories were used for the analysis. A group with ages from 0

122 to 55 years (<56 group, $n=48748$ ) and another group with ages 56 to 103 years-

123 old ( $\geq 56$ group, $n=18570)$. The association of symptoms (presence versus

124 absence) and sex (male versus female) with a RT-PCR positive result for SARS-

125 CoV-2 was studied using multivariate logistic regression analysis considering

126 pairwise interactions, in both age groups. The effect of the different covariates was

127 quantified by the odds ratio values and the corresponding $95 \%$ confidence intervals

128 obtained by logistic regression.

\section{Predictive models}

130 We developed and tested different models aimed to improve the identification of 131 suspected cases; with the premise that such models should have the fewest 132 significant variables and symptoms that could be collected without the need for a 133 physical exam and laboratory testing (e.g. respiratory failure). Odynophagia was 134 excluded from the model design because this symptom alone (that is, without the 
135 option 'sore throat') was recorded only for 10225 individuals, and the exclusion of

136 this symptom did not produce a loss of the predictive capacity of the models.

137 To develop and test the models, the database $(n=67318)$ was randomly divided

138 into two data sets (Training and Testing datasets) with the same percentage of RT-

139 PCR positive cases in each one. The Training set $(n=53854)$ was used for the

140 design and internal validation of the models, while the Testing set $(n=13464)$ was

141 used for external validation and evaluation of the predictive capacity of the model.

142 Models were compared using the Akaike Information Criterion, the area under the

143 receiver-operator characteristic curve $(A \cup C)$ and the predictive value.

144 The best model was chosen through stepwise regression with bidirectional

145 elimination based on AIC. In addition, we performed a 100-fold cross-validation

146 method in which the training base is partitioned in 100 randomly selected subsets

147 and the model is fitted for each one. All statistical analyzes were performed with $\mathrm{R}$

148 (7), and GraphPad Prism version 5.00 for Windows (La Jolla California USA, 149 www.graphpad.com). 


\section{Results}

\section{Data description}

152 A total of 67318 individuals were included in this study; among them, $12 \%$ had a

153 positive RT-PCR for SARS-CoV-2 with a median of 37 years-old (IQR: 26-51), 154 while the group with a negative RT-PCR had a median of 40 years-old (IQR: 25-

155 59). Infection rates varied in different age groups, showing the highest rates in the

15615 to 60 years-old group (Figure 1).

\section{Figure 1: SARS-CoV-2 infection in relation to age}

158 Significant differences were identified in the positivity rate of RT-PCR according to 159 the interval between the onset of symptoms and the time of sampling. It was 160 observed that for the day ranges of $0-3,4-15$ and $16-30$ the proportion of positives 161 was 10.8, 13.7 and $8.6 \%$ respectively. Between the three intervals of days a 162 significant difference was observed $(p<0.01)$

163 The $<56$ group $(n=48748)$ presented a median age of 32 (IQR: $20-42)$, where $16448 \%$ were male and $52 \%$ female while the median age for the $\geq 56$ group $165(\mathrm{n}=18570)$ was 72 (IQR: $63-81,52 \%$ male and $48 \%$ female).

166 The most frequent symptoms for each age group were independent of the RT-PCR 167 result (Figure 2). For the $<56$ group the most frequently observed symptoms were 168 high-grade fever, cough, odynophagia, malaise and headache. For the $\geq 56$ group 169 the most frequent symptoms were high-grade fever, cough, tachypnea, 170 odynophagia and malaise. However, the symptoms with the highest proportion of a 171 confirmatory RT-PCR result were anosmia, dysgeusia, low grade fever, 
172 odynophagia, headache, and cough for the $<56$ group (Figure 3a); and anosmia,

173 dysgeusia, odynophagia and low grade fever for the $\geq 56$ group (Figure $3 b$ ).

174 Figure 2: Frequency of symptoms in the $<56$ group, and $\geq 56$ group. a. whole

175 study population with positive and negative RT-PCR. b. Only individuals with 176 positive RT-PCR. For odynophagia, the analyzed database is restricted to 10255

177 individuals.

178 Figure 3: Proportion (\%) of individuals with positive and negative RT-PCR for

179 SARS-CoV-2 for each of the symptoms used in the database. a. <56 group ( $\mathrm{n}$ :

180 48748). b. $\geq 56$ group ( $\mathrm{n}$ : 18570). For odynophagia, the analyzed database is 181 restricted to 10255 individuals.

\section{Clinical features associated with COVID-19}

183 The association between sex, symptoms and infection with SARS-CoV-2 was 184 studied using logistic regression analysis considering pairwise interactions (see 185 supporting material for details). The odd ratios obtained for each of the symptoms 186 evaluated are displayed in Figure 4 for both age-groups. Sex was significant only 187 for the $<56$ group with males appearing with higher odds than females $(\mathrm{OR}=1.23$ 188 (IC 95\%: 1.07,1.40)). 
medRxiv preprint doi: https://doi.org/10.1101/2020.10.07.20207019; this version posted October 16, 2020. The copyright holder for this preprint (which was not certified by peer review) is the author/funder, who has granted medRxiv a license to display the preprint in perpetuity.

It is made available under a CC-BY-NC-ND 4.0 International license .

189

190

191

192

193

194

195

196

197

198

199

200

201

202

203

204

205

206

207

208

209

210

Figure 4: Odd ratios (OR) of SARS-CoV-2 infection corresponding to the presence of symptoms for (a) $<56$ group and (b) $\geq 56$ group. In green statistically significant ORs ( $p<0.05$ ) and in gray non-significant ORs ( $p>0.05)$. For odynophagia, the analyzed database is restricted to 10255 individuals.

In the $<56$ group the symptoms with a positive association with COVID-19 were anosmia, dysgeusia, headache, low grade fever and cough; while UAMB, tachypnea, conjunctival injection, vomiting, abdominal pain, odynophagia and high grade fever have a negative association. The rest of the symptoms did not show statistical significant association with COVID-19, but some of them have a significant interaction with other symptoms (S2 Table, Supporting material). Significantly higher ORs were found with the combination of anosmia and dysgeusia ( $O R=19.84)$, anosmia and conjunctival injection ( $O R=17.40)$, anosmia and cough $(\mathrm{OR}=9.73)$ and anosmia and malaise $(\mathrm{OR}=6.14)$.

For the $\geq 56$ group, symptoms at presentation with positive association with COVID19 were anosmia, disgeusia, low grade fever and cough, while vomiting, respiratory failure, food refusal, chest pain, tachypnea and dyspnea presented negative association. Other symptoms did not show statistically significant association with COVID-19, but as in the previous case, some have significant interactions (S3 Table, Supporting material). Significantly higher ORs were found with the combination of low-grade fever and irritability $(\mathrm{OR}=14.32)$, and anosmia and dysgeusia $(\mathrm{OR}=6.44)$.

\section{Logistic regression predictive model}


211 We considered several different logistic models for the probability of SARS-CoV-2

212 infection:

$$
p=\frac{1}{1+e^{-A}}
$$

214 where A depends of the set of symptoms considered and other variables like sex, 215 age or days since symptoms onset. All tested models presented similar 216 characteristics regarding area under the curve, AIC value and predictive value.

217 The model with lower AIC value (35029) considers 16 symptoms, sex and three 218 quantitative variables: age, age squared and the number of symptoms (NS) as 219 described in Table 1. Cross validation did not show significant differences between

220 the model calculated with the training set and 100 randomly chosen partitions.

221 The variable age square captures the behavior of the proportion of positive cases

222 with age (Figure 1). An alternative model without the variable age square is 223 described in the supporting material S4 Appendix. It can also be observed that the 224 number of symptoms has a negative contribution in the equation resulting in 225 decreases in the likelihood of COVID-19 infection as the number of symptoms 226 increases. 
Table 1: Characteristics of the logistic regression model. p: probability of being

228 infected with SARS-CoV-2, AUC= Area under the receiver-operator characteristic

229 curve, PPV: predicted positive value, NPV: Negative predicted value.

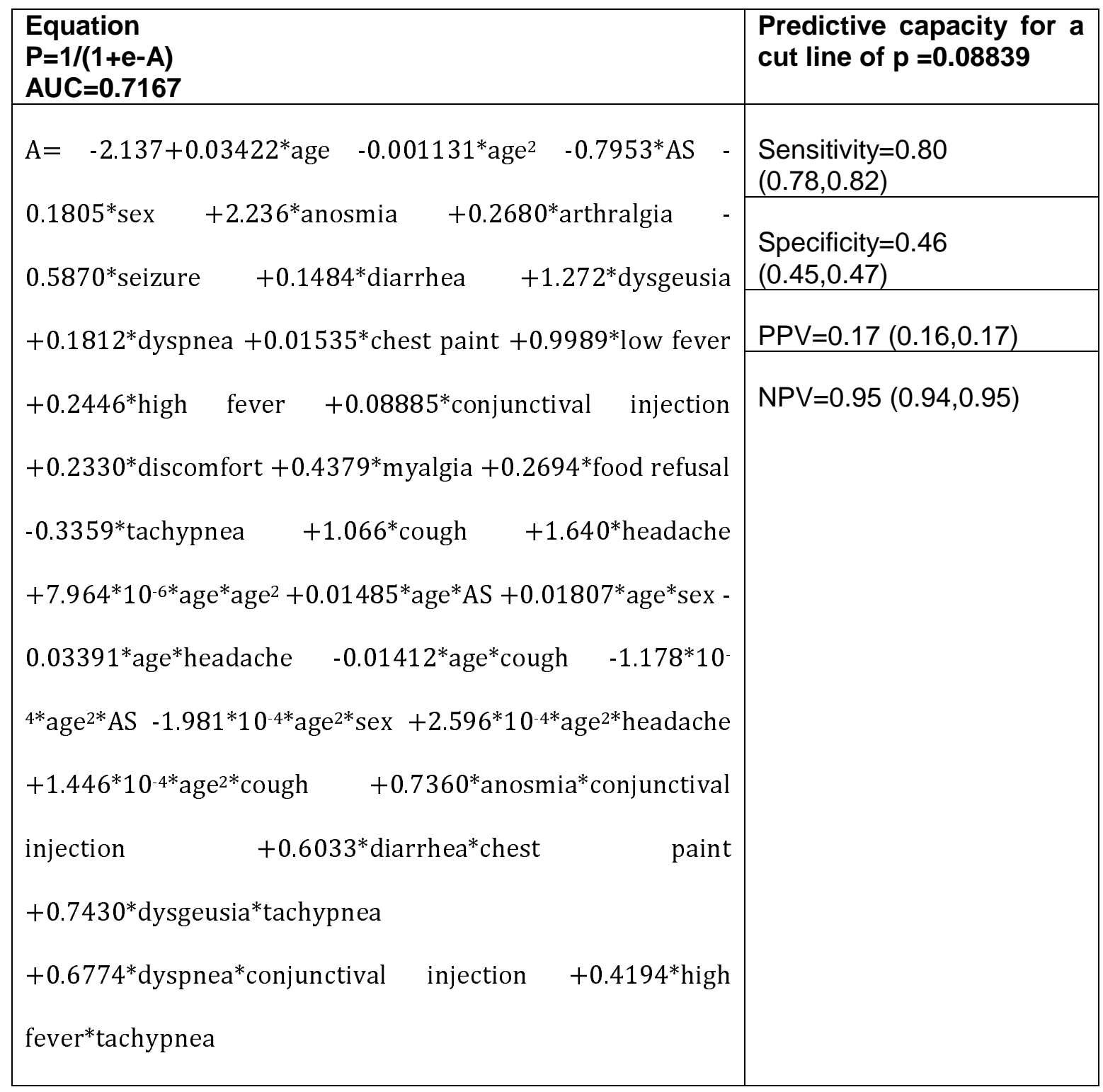


medRxiv preprint doi: https://doi.org/10.1101/2020.10.07.20207019; this version posted October 16, 2020. The copyright holder for this preprint (which was not certified by peer review) is the author/funder, who has granted medRxiv a license to display the preprint in perpetuity.

It is made available under a CC-BY-NC-ND 4.0 International license .

\section{Discussion}

232 The analysis of this large cohort allows an age-based characterization of the 233 symptoms associated with COVID-19 at presentation, in the search for an 234 improved clinical based decision strategy for the use of diagnostic tests and case

235 management. To interrupt the spread of SARS-CoV-2, early detection, isolation, 236 and the implementation of a robust system to trace contacts is required ( $\mathrm{WHO}$, 237 2020). Among the non-severe symptomatic cases, non-specific symptoms shared 238 with other acute upper-respiratory infections hamper proper case identification and 239 implementation of rapid isolation measures. In contrast to most acute upper240 respiratory infections (including many respiratory coronaviruses), COVID-19 poses

241 a special challenge in requiring specific identification for clinical and public health 242 management. To facilitate the early detection of patients with COVID-19, we 243 analyzed the symptoms of 67318 individuals studied with RT-PCR, of which $12 \%$ 244 had a positive test result.

245 The most frequently reported symptoms among case series of COVID-19 include 246 fever, cough, dyspnea and shortness of breath $(8,9)$. Other symptoms include sore 247 throat, diarrhea, nausea, vomiting, myalgia, headache and confusion (8). We found 248 that in the present database the most frequent symptoms were cough, high-grade 249 fever, and odynophagia. However, more frequent symptoms not necessarily are 250 indicators of COVID-19. Our analysis revealed that the symptoms positively 251 associated with COVID-19 are anosmia, dysgeusia, low grade fever (37.5 to 38 $252 \stackrel{\circ}{-})$, cough and headache (the later only in the $<56$ group). Another group of 253 symptoms show a negative association with a positive RT-PCR for SARS-CoV-2, 
medRxiv preprint doi: https://doi.org/10.1101/2020.10.07.20207019; this version posted October 16, 2020. The copyright holder for this preprint (which was not certified by peer review) is the author/funder, who has granted medRxiv a license to display the preprint in perpetuity.

It is made available under a CC-BY-NC-ND 4.0 International license .

254 therefore suggesting alternative diagnoses (Figure 3). Our analysis also revealed

255 that some symptoms interact with each other, modifying their ORs. In relation to 256 this, anosmia and dysgeusia were observed to have a significant and positive 257 interaction increasing the already high and positive OR of each of them. This is in 258 accordance with other authors stating that anosmia and dysgeusia have a positive 259 predictive value of $77 \%$ each of them and $83 \%$ if they are together (10). Although anosmia can appear in other AURI, it has been suggested that the lack of accompanying rhinitis or nasal swelling is more typically associated with COVID-19

262 (11); we were not able to test this hypothesis because the questionnaire does not 263 contain rhinitis as a variable. Another combined effect to be highlighted was 264 anosmia and conjunctival injection in the $<56$ age group and low-grade fever and 265 irritability in the elder group. These combinations showed ORs $>14$. Low grade 266 fever had a positive association with COVID-19 in both age groups, while high 267 grade fever $\left(\geq 38^{\circ} \mathrm{C}\right)$ showed a negative association in the $<56$ group and was not 268 significant in the $\geq 56$ group.

269 In this study we also developed a model based on symptoms at presentation, sex 270 and age. In our database, patient's age was found as a significant variable for

271 establishing correlations between symptoms and COVID-19. Although the age272 dependent variability in the proportion of RT-PCR positive results in our study 273 population might reflects differences in exposure due to school closure and an 274 active protection of the elder, the model achieves comparable predictive values in 275 all age groups. In view of the burden of morbidity and mortality in high risk groups, 276 models to predict the likelihood of infection should be interpreted with caution and 
medRxiv preprint doi: https://doi.org/10.1101/2020.10.07.20207019; this version posted October 16, 2020. The copyright holder for this preprint (which was not certified by peer review) is the author/funder, who has granted medRxiv a license to display the preprint in perpetuity.

It is made available under a CC-BY-NC-ND 4.0 International license .

277

278 disease.

279 This study was conducted with patients diagnosed between April and May 2020,

280 prior to the influenza season in Argentina; this should also place our results in the 281

282

284

285

286

287

288

289

290

291

292

294

295

296

297

298

299

not be used to limit the corresponding testing of groups at increased risk of severe adequate context of the alternative diagnoses that could modify the specificity of the symptoms based on the type and prevalence of these agents; in the current case, with most cases occurring in Buenos Aires and its metropolitan area, this same area was affected by its largest recorded dengue outbreak and a significant reduction of influenza-like illnesses (12).

This study has limitations; the diagnostic test of choice, RT-PCR shows a sensitivity of $56-83 \%$ (13); therefore, the sensitivity and specificity measures of the model may lose precision. While suffering from the lack of a highly sensitive diagnostic standard, identifying clinical characteristics that raise the pretest probability of the infection could help interpretations of the RT-PCR result when combined with predictive models, epidemiological factors and complementary diagnostic methods like chest imaging (14). In our analysis, a significantly higher probability of a positive RT-PCR was identified if the test was performed when the interval between symptoms initiation and sampling was between 4 and 15 days. Another limitation derives from the circumstance of the data collection, which has not been design as a prospective research tool but rather as a surveillance system with no monitoring system and therefore subject to errors in upload.

In summary, this symptoms-based analysis of a cohort tested for COVID-19 identified a group of symptoms (anosmia/dysgeusia, low-grade fever, cough and 
medRxiv preprint doi: https://doi.org/10.1101/2020.10.07.20207019; this version posted October 16, 2020. The copyright holder for this preprint (which was not certified by peer review) is the author/funder, who has granted medRxiv a license to display the preprint in perpetuity. It is made available under a CC-BY-NC-ND 4.0 International license .

300 headache) with significant association with a positive RT-PCR. These findings

301 show that a regression model based on multiple factors (age, sex, interaction

302 between symptoms) could be used as a complementary method for the rapid

303 identification of possible COVID-19 cases and the necessary precautionary

304 measures. 


\section{References}

306 1. World Health Organization (WHO). Novel Coronavirus ( 2019-nCoV )

307 Situation Report - 121 February 2020. WHO Bull. 2020;(JANUARY):1-7.

308 2. Hopkins C for SS and E (CSSE) J. COVID-19 Map - Johns Hopkins https://coronavirus.jhu.edu/map.html

3. Pascarella G, Strumia A, Piliego C, Bruno F, Del Buono R, Costa F, et al. COVID-19 diagnosis and management: a comprehensive review. Vol. 2019, Journal of Internal Medicine. 2020. 0-2 p.

4. Ai T, Yang Z, Hou H, Zhan C, Chen C, Lv W, et al. Correlation of Chest CT and RT-PCR Testing in Coronavirus Disease 2019 (COVID-19) in China: A

5. Zhang JJ, Cao YY, Dong X, Wang BC, Liao MY, Lin J, et al. Distinct characteristics of COVID-19 patients with initial rRT-PCR positive and

6. Yang R, Gui X, Xiong Y. Comparison of Clinical Characteristics of Patients with Asymptomatic vs Symptomatic Coronavirus Disease 2019 in Wuhan,

7. $\mathrm{R}$ Core Team. R: A language and environment for statistical computing. $\mathrm{R}$ 
8. Wu YC, Chen CS, Chan YJ. The outbreak of COVID-19: An overview. J Chinese Med Assoc. 2020;83(3):217-20.

9. $\quad$ Yang J, Zheng Y, Gou X, Pu K, Chen Z, Guo Q, et al. Prevalence of comorbidities and its effects in coronavirus disease 2019 patients: A systematic review and meta-analysis. Int J Infect Dis. 2020;94:91-5.

10. Zayet S, Klopfenstein T, Mercier J, Kadiane-Oussou NJ, Lan Cheong Wah L,

Royer P-Y, et al. Contribution of anosmia and dysgeusia for diagnostic of COVID-19 in outpatients. Infection. 2020;(0123456789):0-4.

11. Zubair AS, McAlpine LS, Gardin T, Farhadian S, Kuruvilla DE, Spudich S. Neuropathogenesis and Neurologic Manifestations of the Coronaviruses in the Age of Coronavirus Disease 2019: A Review. JAMA Neurology.

12. Boletín integral de vigilancia. Edición semanal.499 Boletín Integrado de Vigilancia. 2020 [cited 2020 Jul 7]. Available from: https://www.argentina.gob.ar/sites/default/files/biv_499_se23.pdf

13. Kokkinakis I, Selby K, Favrat B, Genton B, Cornuz J. [Covid-19 diagnosis $\square$ : clinical recommendations and performance of nasopharyngeal swab-PCR]. Rev Med Suisse. 2020;16(689):699—701. 
medRxiv preprint doi: https://doi.org/10.1101/2020.10.07.20207019; this version posted October 16, 2020. The copyright holder for this preprint (which was not certified by peer review) is the author/funder, who has granted medRxiv a license to display the preprint in perpetuity. It is made available under a CC-BY-NC-ND 4.0 International license.

347 Supporting information captions

348

349

351

352

353

354
- S1 STROBE Checklist.

- S2 Table. Logistic regression for the group with ages from 0 to 55 years (<56 group, $\mathrm{n}=48748)$.

- S3 Table. Logistic regression for the group with ages from 56 to 103 yearsold ( $\geq 56$ group, $n=18570)$.

- S4 Appendix. Alternative model with the variables sex, age, 20 symptoms and pairwise interactions. 


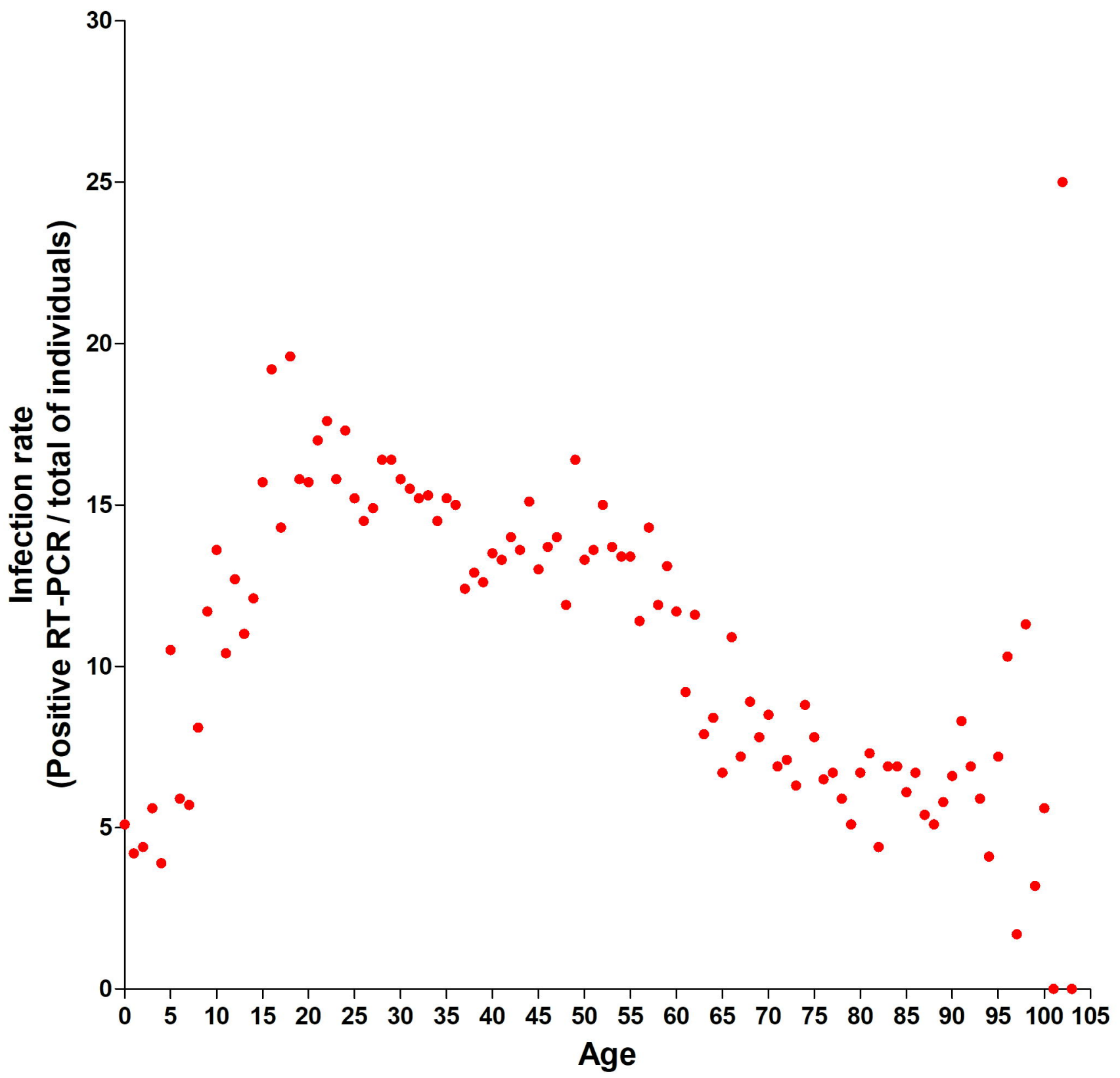


a.

\section{$<56$ years group}

$>=56$ years group

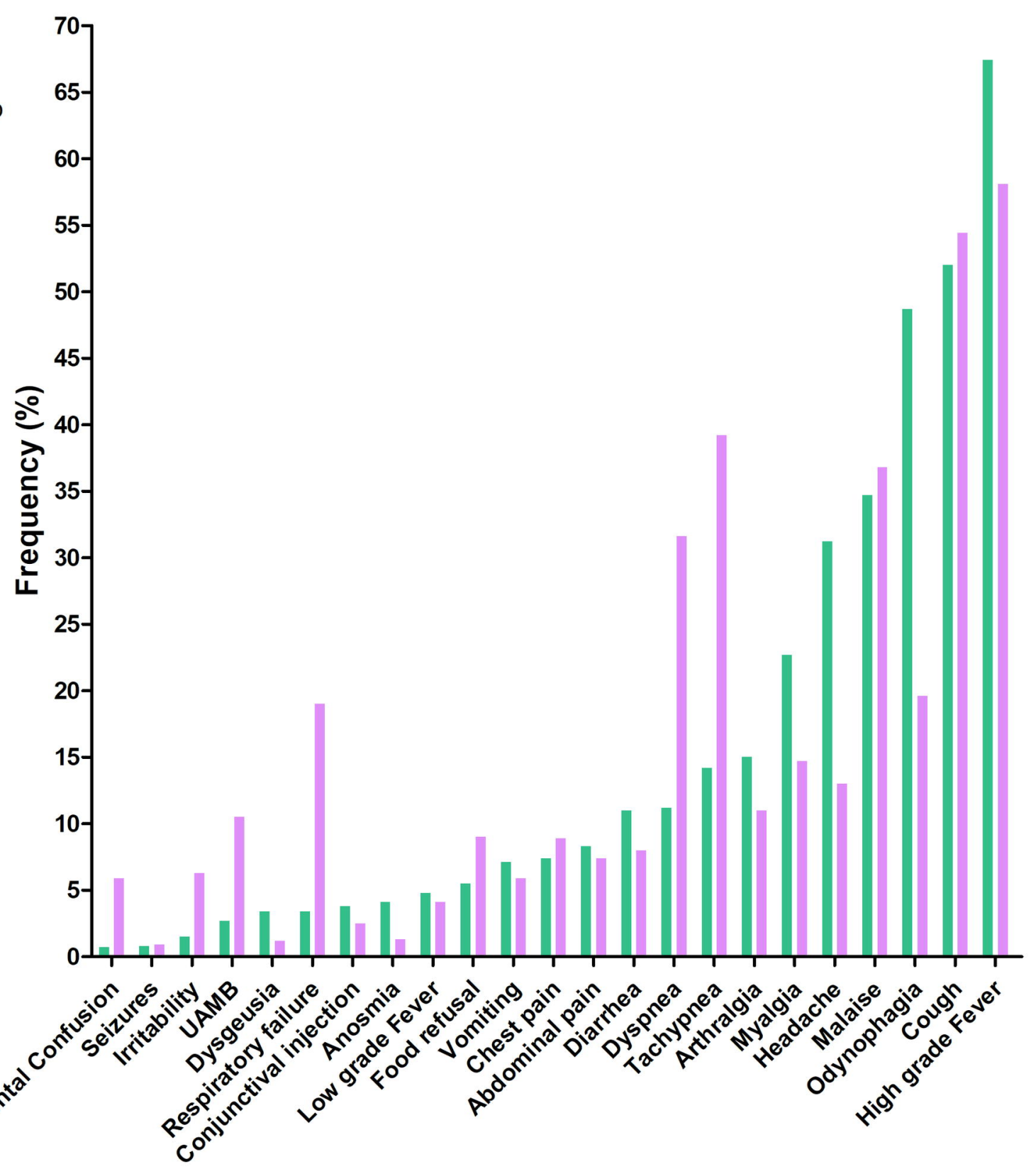


b.

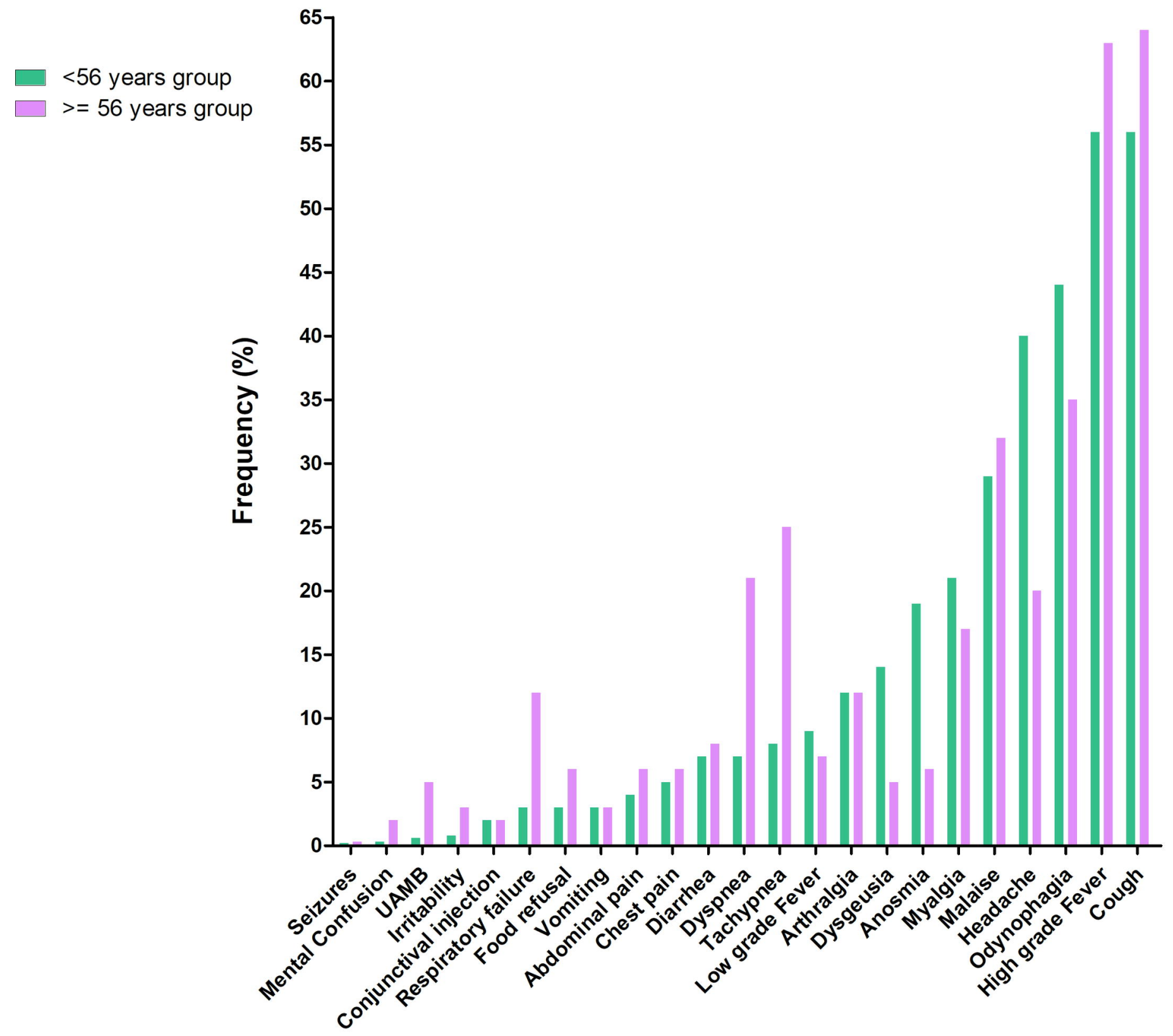


a.

$\square$ RT-PCR

SARS-CoV-2

Positive

RT-PCR

SARS-CoV-2

Negative

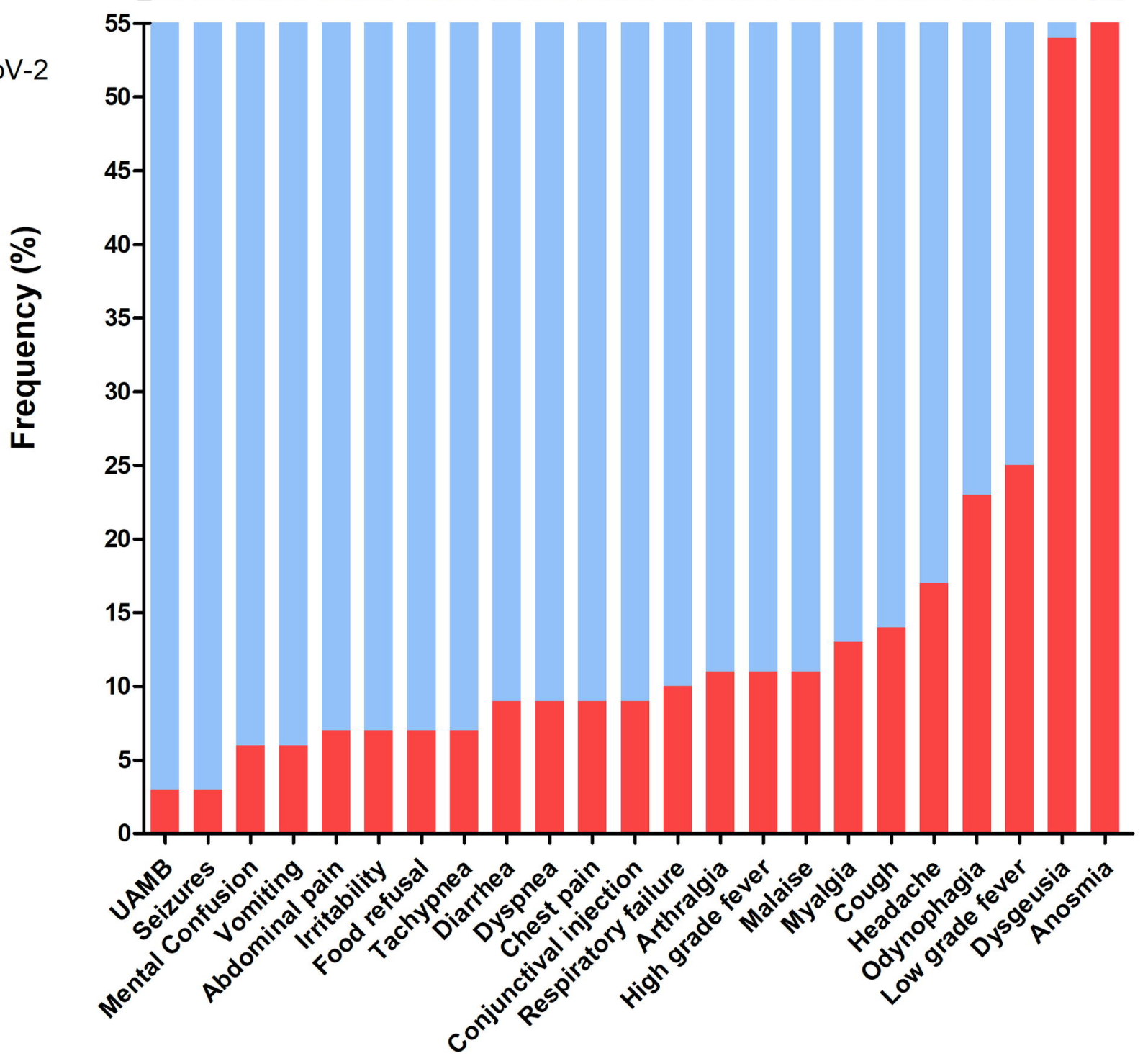

Symptoms 
b.

RT-PCR

SARS-CoV-2

Positive

RT-PCR

SARS-CoV-2

Negative
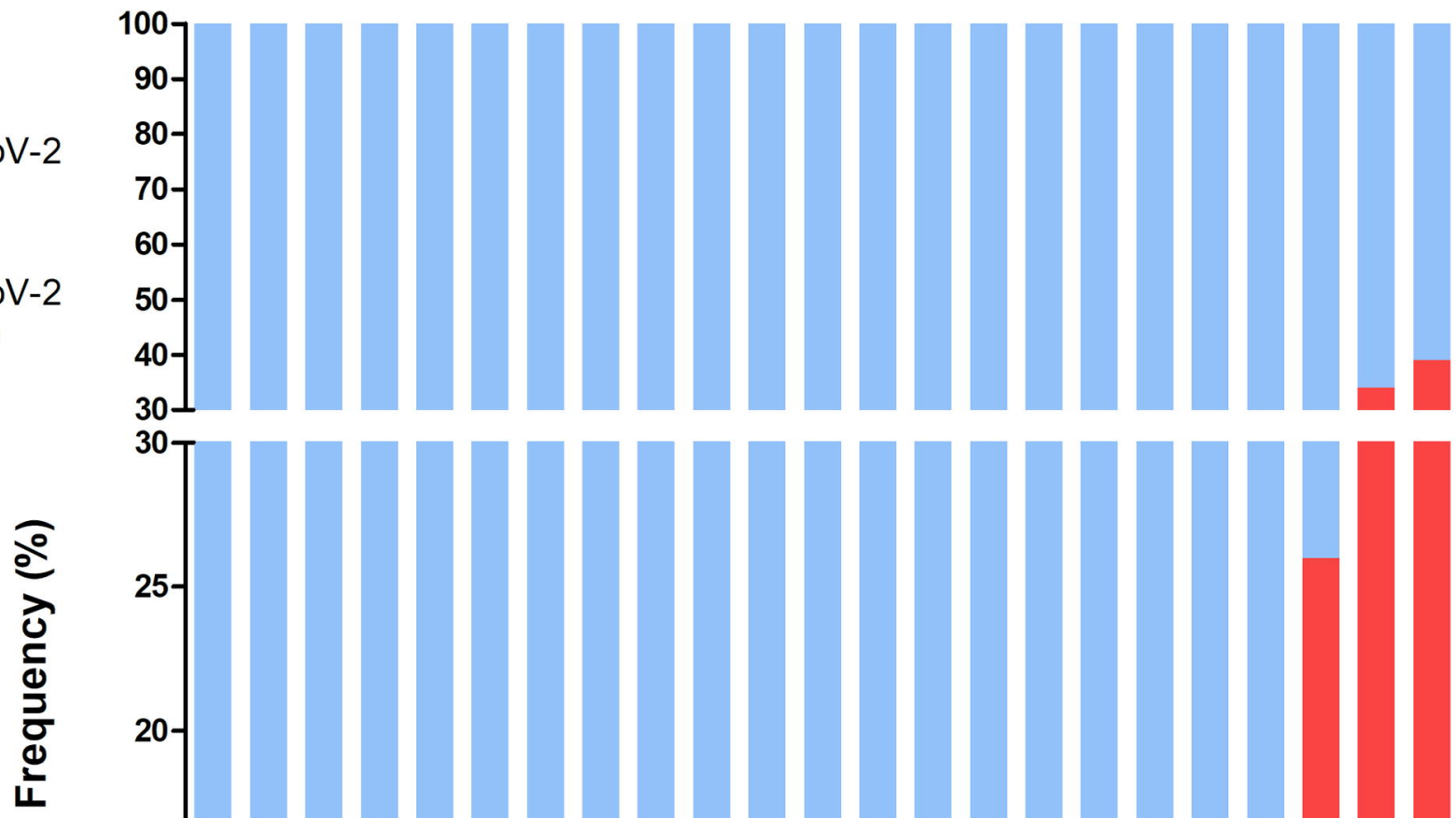

15-

$5-$
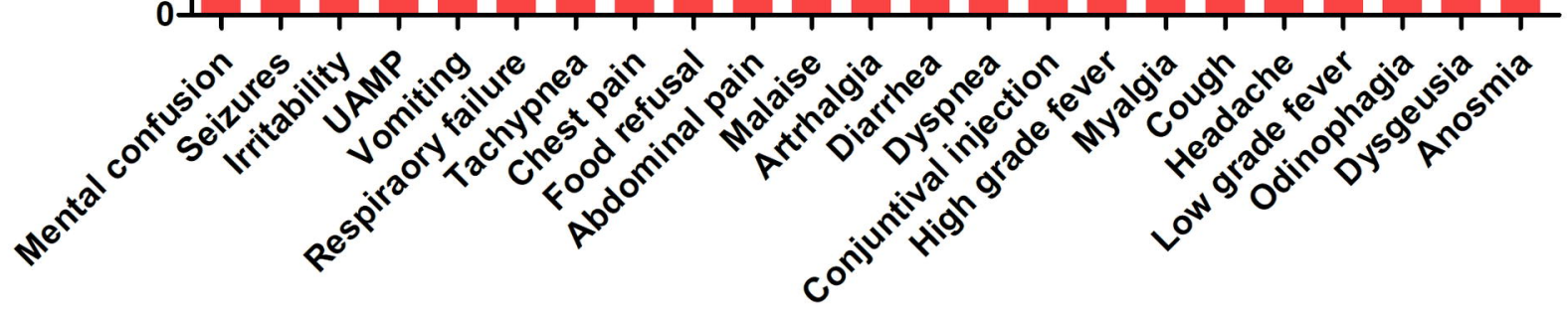

Symptoms 


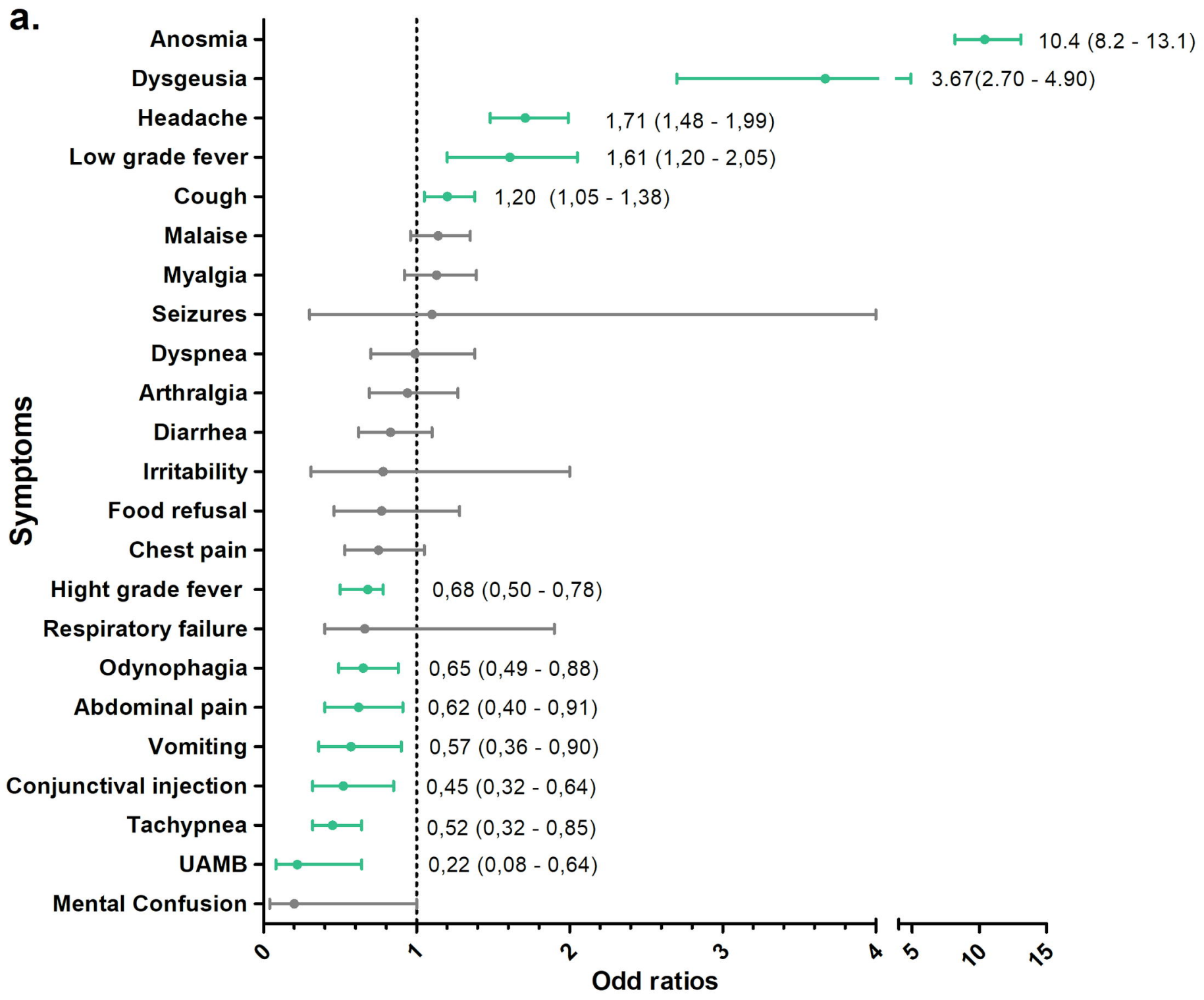


b.

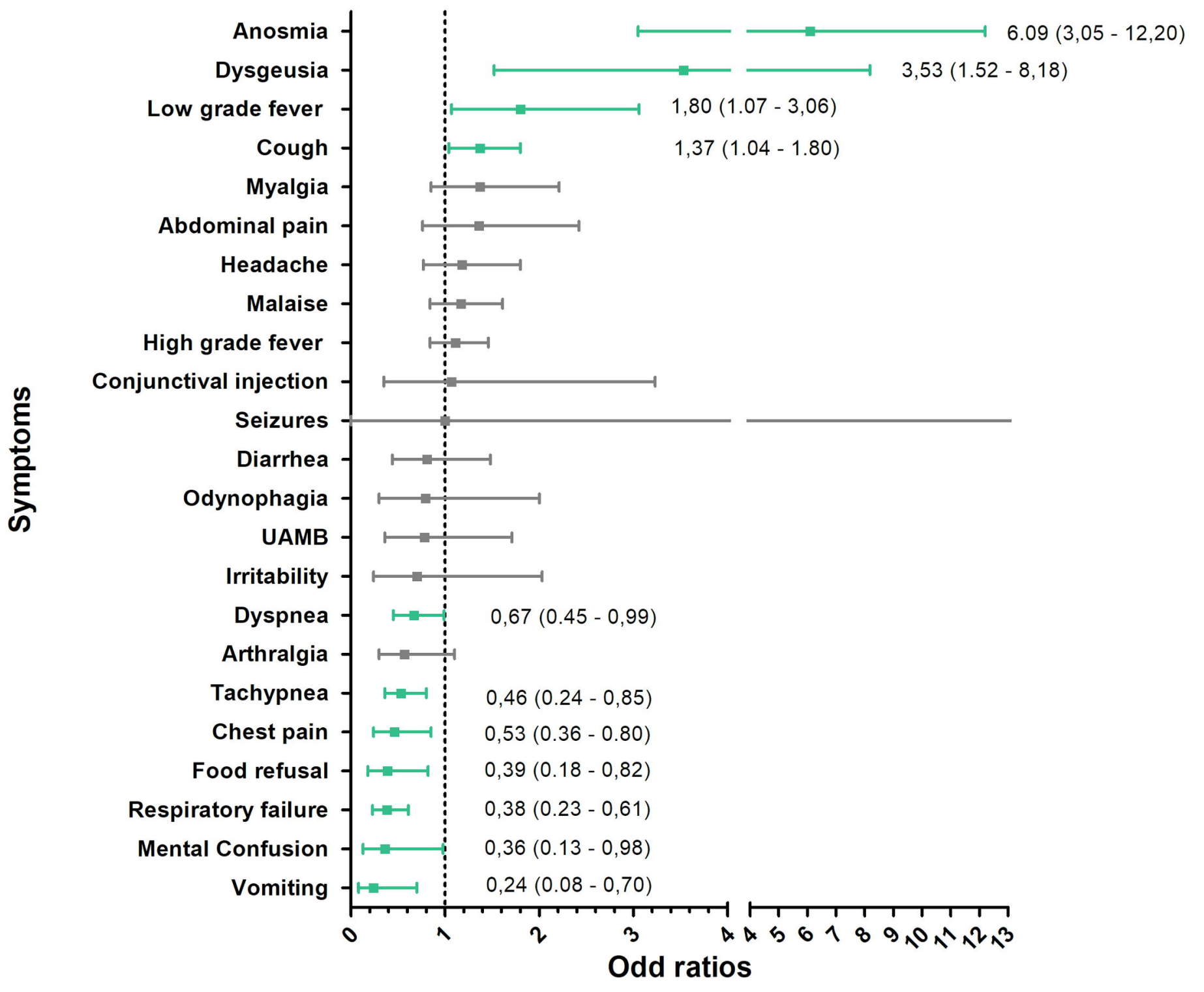

